
p.290-293, abr-jun 2005.

\title{
Qualidade de raízes de cenoura em sistemas consorciados com alface sob diferentes densidades populacionais
}

\author{
Aurélio P. Barros Júnior; Francisco Bezerra Neto; Ebenézer de O. Silva; Maria Zuleide de Negreiros; \\ Eliane Q. de Oliveira; Lindomar Maria da Silveira; Jailma S.S. de Lima; Karidja K.C. de Freitas \\ ESAM, NPG, C. Postal, 137, 59625-900 Mossoró-RN; E-mail: bezerra@esam.br
}

\section{RESUMO}

O experimento foi realizado de junho a setembro de 2003, em campo da ESAM, com o objetivo de avaliar a qualidade de raízes de cenoura (Brasília) em sistemas consorciados com alface (Tainá) sob diferentes densidades populacionais. $\mathrm{O}$ delineamento experimental utilizado foi de blocos casualizados, em esquema fatorial $4 \times 4$, com três repetições. Os tratamentos foram resultantes da combinação de quatro populações de cenoura $[(40 \%, 60 \%, 80 \%$ e $100 \%$ da população recomendada no cultivo solteiro (PRCS)] com quatro populações de alface $(40 \%, 60 \%, 80 \%$ e $100 \%$ da PRCS). As características avaliadas nas raízes da cenoura foram acidez total titulável (ATT), sólidos solúveis totais (SST), açúcares totais (ACT) pH, relação sólidos solúveis totais e acidez total titulável, além da produtividade comercial da cenoura e da alface. Ocorreu interação significativa entre as densidades populacionais das culturas componentes na ATT das raízes da cenoura. Houve aumento no conteúdo de SST e no pH à medida que se aumentou a densidade populacional de cenoura. Houve também um aumento na produtividade comercial de raízes de cenoura e na produtividade da alface com o aumento de suas densidades populacionais, respectivamente. A variação na população de cenoura não afetou a produtividade da alface, mas a variação na população da alface afetou negativamente a produtividade comercial da cenoura. Entre as características avaliadas, as que se correlacionaram de maneira significativa com a produtividade comercial de cenoura, foram as concentrações de sólidos solúveis totais e açucares totais, evidenciando assim, que estes atributos podem ser considerados representativos da qualidade de raízes da cenoura.

Palavras-chave: Daucus carota, Lactuca sativa, composição química.

\begin{abstract}
Quality of carrot roots in intercropped systems with lettuce under different planting densities

The experiment was carried out from June to September 2003, in Mossoró, Rio Grande do Norte State, Brazil, to evaluate the quality of carrot roots (cv. Brasília) in intercropped systems with lettuce (cv. Tainá) under different planting densities. The experimental design used was of randomized blocks in a $4 \times 4$ factorial scheme with three replications. The treatments consisted of the combination of four carrotplanting densities $[(40 \%, 60 \%, 80 \%$ and $100 \%$ of the recommended sole crop density (RSCD)] with four lettuce-planting densities (40\%, $60 \%, 80 \%$ and $100 \%$ of RSCD). The evaluated quality characteristics of the carrot roots were: titrable total acidity (TTA), total soluble solids (TSS), total sugars (TSU), pH, and TSS/TSS ratio, besides commercial productivity of carrot roots and lettuce yield. There was a significant interaction between carrot planting-densities and lettuce-planting densities on TSS of carrot roots. The TTS content and $\mathrm{pH}$ increased with increasing carrot-planting densities. Commercial productivity of carrot roots and lettuce yield also increased with increasing in planting densities. The variation in the carrot planting density did not influence lettuce yield but the variation in the lettuce planting density negatively influenced commercial productivity of carrot roots. Among the assessed characteristics, TSS and TSS were significantly correlated with commercial productivity, showing that these traits may be representative of carrot root quality.
\end{abstract}

Keywords: Daucus carota, Lactuca sativa, chemical composition.

(Recebido para publicação em 22 de abril de 2004 e aceito em 7 de abril de 2005)

$\mathrm{E}$ ntre as culturas olerícolas que se podem combinar com vantagens agroeconômicas e ambientais estão as hortaliças alface e cenoura (ANDRADE et al. 2001; OLIVEIRA, 2003; BEZERRA NETO et al. 2003). Elas têm elevado valor nutricional e são bastante usadas na alimentação humana, contribuindo primariamente com vitaminas e sais minerais.

Alguns trabalhos de sistemas consorciados, utilizando cenoura e alface como culturas companheiras, têm sido realizados em alguns estados brasileiros, estudando o efeito de vários fatores, tais como cultivares, grupos de cultivares e arranjos espaciais, na produti- vidade e componentes da produção (CAETANO et al. 1999; OLIVEIRA 2003; OLIVEIRA 2004). Um dos questionamentos que se tem levantado, é se os fatores tratamentos, assim como diferentes densidades populacionais das culturas componentes, como as que estão sendo propostas neste trabalho, podem afetar o valor das características químicas das culturas companheiras.

Segundo Baardseth et al. (1995) a composição química das raízes de cenoura é variável e influenciada por fatores genéticos e pelas condições de cultivo tais como: sistemas de cultivos, tipos e propriedades físicas do solo, data de plantio, temperatura durante a estação de crescimento da cultura e período de crescimento entre outros. Por outro lado, Robinson e Decker-Walters (1997), trabalhando com cucurbitáceas, mencionaram que além dos fatores citados acima, existem outros como aspectos fitossanitários e densidade de plantio que comprovadamente podem influenciar a qualidade da hortaliça.

Machado et al. (2003), avaliando a influência do espaçamento na quantidade de açucares e sólidos solúveis totais em cenoura solteira, utilizando as densidades de plantio de $14,16,18$ e 20 plantas por metro de fileira, verificaram 
que a concentração de açucares totais variou entre $3,2 \%$ e $3,6 \%$ para cultivar Nantes e de $3,5 \%$ a $3,9 \%$ para a cultivar Alvorada. Os valores de sólidos solúveis totais variaram de 6,5 a $7,5^{\circ} \mathrm{BRIX}$ para cultivar Nantes e $6,2{ }^{\circ}$ BRIX a 7,3 'BRIX para 'Alvorada'. Por outro lado, não se encontraram na literatura, trabalhos estudando as características de qualidade de hortaliças em sistemas consorciados.

A fim de obter subsídios sobre a qualidade de hortaliças em sistemas consorciados, o presente trabalho visa avaliar a qualidade de raízes de cenoura em sistemas consorciados com alface sob diferentes densidades populacionais.

\section{MATERIAL E MÉTODOS}

O experimento foi realizado na horta da ESAM, de junho a setembro de 2003, em um Argissolo Vermelho Amarelo Eutrófico. As características do solo da área experimental foram: $\mathrm{pH}$ (água $1: 2,5)=8,49 ; \mathrm{Ca}=7,12 \mathrm{cmol}_{\mathrm{c}} \mathrm{dm}^{-3} ; \mathrm{Mg}$ $=4,48 \mathrm{cmol}_{\mathrm{c}} \mathrm{dm}^{-3} ; \mathrm{K}=1,64 \mathrm{cmol}_{\mathrm{c}} \mathrm{dm}^{-3}$; $\mathrm{Na}=0,24 \mathrm{cmol}_{\mathrm{c}} \mathrm{dm}^{-3} ; \mathrm{Al}=0,00 \mathrm{cmol}_{\mathrm{c}}$ $\mathrm{dm}^{-3}$ e $\mathrm{P}=382,7 \mathrm{mg} \mathrm{dm}^{-3}$.

$\mathrm{O}$ delineamento experimental utilizado foi de blocos casualizados com três repetições, sendo os tratamentos arranjados em esquema fatorial 4 x 4 . Os tratamentos resultaram da combinação de quatro populações de plantas de cenoura $[(40 \%, 60 \%, 80 \%$ e $100 \%$ da população recomendada no cultivo solteiro (PRCS)] com quatro populações de plantas de alface $(40 \%, 60 \%, 80 \%$ e $100 \%$ da PRCS). A alface foi semeada em dois cultivos sucessivos, uma no início da cultura da cenoura e outra no final do ciclo. Os níveis populacionais recomendados no cultivo solteiro foram 500.000 plantas/ha para a cenoura (SIQUEIRA, 1995) e 250.000 plantas/ ha para a alface (SILVA, 1999).

Cada parcela constituiu-se de duas faixas com quatro fileiras (uma de cenoura e outra de alface). A bordadura constituiu-se de uma fileira em cada lado da parcela. A área total da parcela foi $1,92 \mathrm{~m}^{2}$, com uma área útil de 1,60 m². $\mathrm{O}$ espaçamento de plantio, bem como o número de plantas na área útil, variaram de acordo com cada nível populacional em cada combinação en- tre as populações de cenoura e alface.

A cultivar de cenoura usada foi a Brasília, indicada para a região Nordeste (Vieira et al.,1983). Ela apresenta folhagem verde escura, raízes cilíndricas com coloração laranja-clara e baixa incidência de ombro verde ou roxo, resistente ao calor, à requeima por Alternaria e ao pendoamento prematuro. A cultivar de alface utilizada foi a Tainá, indicada para o mercado de consumo fresco, devido ao excelente sabor. Caracteriza-se pela boa capacidade produtiva, cabeças grandes, boa formação de ombro e alta resistência ao pendoamento precoce (SEMENTES SAKAMA, 2002).

Antes da instalação do experimento em campo, foi realizada uma solarização na área de plantio, durante 60 dias, visando evitar ou reduzir a população de fitopatógenos do solo, que viessem a prejudicar a produtividade da cultura da cenoura. Durante a condução do experimento, foram efetuadas capinas manuais e irrigação pelo sistema de microaspersão.

Nos canteiros de plantio, foram realizadas a adubação orgânica com 80 t/ ha de esterco de bovinos e a química com $40 \mathrm{~kg} / \mathrm{ha}$ de nitrogênio, na forma de uréia, $60 \mathrm{~kg} / \mathrm{ha}$ de $\mathrm{P}_{2} \mathrm{O}_{5}$, na forma de superfosfato simples e $30 \mathrm{~kg} / \mathrm{ha}$ de $\mathrm{K}_{2} \mathrm{O}$, na forma de cloreto de potássio, de acordo com a análise realizada no solo e recomendações do IPA (IPA 1998).

Foram realizadas duas adubações nitrogenadas em cobertura na cenoura, uma aos 25 dias após o plantio e a outra aos 45 dias com $40 \mathrm{~kg} / \mathrm{ha}$ de nitrogênio na forma de uréia. Junto com a primeira adubação de cobertura nitrogenada, foi realizada paralelamente uma adubação potássica de $30 \mathrm{~kg} / \mathrm{ha}$ de $\mathrm{K}_{2} \mathrm{O}$.

A cenoura, cultura principal, foi semeada em 12/06/2003. O desbaste foi realizado 25 dias após a semeadura, deixando-se apenas uma planta por cova.

Foram realizados dois cultivos sucessivos de alface em consórcio com a cenoura. Para isso, as mudas foram preparadas com semeaduras, em 30/06 e 08/ 08/2003, em copos descartáveis de 150 $\mathrm{ml}$, contendo como substrato comercial uma mistura de fibra de coco e composto orgânico na proporção de 1:2. Foram semeadas de três a cinco sementes por recipiente e aos três dias após a germi- nação efetuou-se o primeiro desbaste, deixando-se duas plântulas/recipiente, e aos oito dias o segundo desbaste, deixando-se apenas uma plântula/recipiente. As mudas foram produzidas sob sombreamento, utilizando-se uma estufa coberta com plástico branco. As mudas de alface do primeiro cultivo foram transplantadas para as faixas adjacentes da cenoura aos 24 dias após a semeadura e as do segundo cultivo aos 18 dias após a semeadura, quando a cenoura se encontrava com 11 e 75 dias da semeadura, respectivamente.

A colheita da cenoura foi realizada em 08/09/2003, com um ciclo de 88 dias após o plantio. A colheita da alface no primeiro cultivo foi realizada nos dias 21 e 22/07/2003, estando a cultura da cenoura aos 39 dias do plantio e a alface aos 52 e 53 dias da semeadura. No segundo cultivo, a colheita foi realizada nos dias 18 e 19/09/2003, aos 41 e 42 dias da semeadura.

Além da produtividade comercial da cenoura e da alface, as características de qualidade das raízes da cenoura, tais como: sólidos solúveis totais (SST), açúcares totais (ACT) pH, acidez total titulável (ATT) e a relação sólidos solúveis totais e acidez total titulável (SST/ATT) foram avaliadas.

Uma análise de variância univariada para o delineamento de blocos casualizados em esquema fatorial foi utilizada para avaliar as características de raízes da cenoura, através do software SPSS/PC (NORUSIS, 1990). Os efeitos dos fatores densidades populacionais foram avaliados pelos procedimentos de ajustamento de curvas de resposta através do software Table Curve Package (JANDEL SCIENTIFIC, 1991). Uma análise de correlação linear foi realizada entre a produtividade comercial da cenoura e as características de qualidade de raízes.

\section{RESULTADOS E DISCUSSÃO}

Ocorreu interação significativa entre as populações de cenoura e de alface somente para ATT de raízes de cenoura (Tabela 1). Procedeu-se um ajustamento de regressão simples ou de superfície de resposta, em função das densidades populacionais estudadas em cada cultura.

Desdobrando esta interação em função das populações de alface dentro das 
Tabela 1. Equações de regressão ajustadas para acidez total titulável (ATT), sólidos solúveis totais (SST), açucares totais (ACT), pH, relação sólidos solúveis totais e acidez total titulável (SST/ATT), produtividade comercial de cenoura (PDC), produtividade da alface no primeiro $\left(\mathrm{PDA} 1^{\circ} \mathrm{C}\right)$ e segundo $\left(\mathrm{PDA} 2^{\circ} \mathrm{C}\right)$ cultivo em função das densidades populacionais das culturas componentes. Mossoró-RN, ESAM, 2004.

\begin{tabular}{|c|c|c|}
\hline Características & Equações de regressão & $\mathbf{R}^{2}$ \\
\hline \multicolumn{3}{|l|}{ ATT (\%) } \\
\hline${ }^{*}$ Pop. Alface dentro Pop. Cenoura $40 \%$ & $Y=0,15^{*}+0,67 \cdot 10-5^{*} \times 2$ & $0,98^{*}$ \\
\hline Pop. Alface dentro Pop. Cenoura $60 \%$ & $y=0,17^{*}-59,18^{*} / x 2$ & $0,69^{*}$ \\
\hline Pop. Alface dentro Pop. Cenoura $80 \%$ & Nenhuma função encontrada & - \\
\hline Pop. Alface dentro Pop. Cenoura 100\% & $y=0,30^{*}-0,14 \cdot 10-4^{*} \times 2-180,32^{*} / x 2$ & $0,99^{*}$ \\
\hline${ }^{*}$ Pop. Cenoura dentro Pop. Alface $\quad 40 \%$ & Nenhuma função encontrada & - \\
\hline Pop. Cenoura dentro Pop. Alface $60 \%$ & Nenhuma função encontrada & - \\
\hline Pop. Cenoura dentro Pop. Alface $80 \%$ & Nenhuma função encontrada & - \\
\hline Pop. Cenoura dentro Pop. Alface $100 \%$ & Nenhuma função encontrada & - \\
\hline SST (oBrix) em função Pop. Cenoura & $y=8,09^{*}-0,676 \cdot 10-4^{*} x 2$ & $0,75^{\star}$ \\
\hline SST (oBrix) em função Pop. Alface & Nenhuma função encontrada & - \\
\hline ACT (\%) em função Pop. Cenoura & $y 2=10,83^{*}-24,78^{*} / x$ & $0,60^{*}$ \\
\hline ACT (\%) em função Pop. Alface & Nenhuma função encontrada & - \\
\hline pH em função Pop. Cenoura & $y 2=38,29^{*}-347,98^{*} / x 2$ & $0,66^{*}$ \\
\hline pH em função Pop. Alface & Nenhuma função encontrada & - \\
\hline SST/ATT em função Pop. cenoura & Nenhuma função encontrada & - \\
\hline SST/ATT em função Pop. Alface & Nenhuma função encontrada & - \\
\hline PDC (t/ha) em função Pop. Cenoura e & $y=9,62^{*}+0,46^{*} x-0,0013^{*} x 2-0,16^{*} z+0,0011^{*} z 2$ & $0,99^{*}$ \\
\hline Alface & & $0,99^{*}$ \\
\hline PDA1oC (t/ha) em função Pop. Cenoura & $y=38,85^{*}-784,11^{*} / x$ & - \\
\hline PDA1oC (t/ha) em função Pop. Alface & Nenhuma função encontrada & $0,99^{*}$ \\
\hline PDA2oC (tha) em função Pop. Cenoura & $y=9,57^{*}-261,82^{*} / x$ & - \\
\hline PDA2oC (t/ha) em função Pop. Alface & Nenhuma função encontrada & \\
\hline
\end{tabular}

populações de cenoura, foi observado um comportamento crescente da ATT com o aumento das populações de alface dentro da população de cenoura de $40 \%$ PRCS. Situação inversa ocorreu com esta característica dentro da população de cenoura de 60\% PRCS (Tabela 1). Esta diminuição na acidez total titulável na cenoura se deve presumilvemente a sua maior população em relação ao nível anterior, combinada com o aumento da população da alface, diminuindo assim, os teores de ácidos orgânicos em decorrência da maior pressão de competição entre as culturas. Sabe-se que, as densidades mais altas reduzem a área foliar, conseqüentemente à taxa fotossintética, promovendo assim um decréscimo no conteúdo dos ácidos orgânicos nas raízes de cenoura (NICHOLS, 1988).

Não se encontrou nenhuma função resposta para expressar o comportamento desta característica em função das populações de alface dentro da população de cenoura de $80 \%$ PRCS. Dentro da população de cenoura de $100 \%$ PRCS, a ATT aumentou com o aumento das populações de alface, atingindo um valor máximo de $0,19 \%$ na população de alface de $60 \%$ PRCS, decrescendo de valor à medida que se aumentou a população de alface (Tabela 1).

Por outro lado, desdobrando-se a interação da ATT em função das populações de cenoura dentro das populações de alface, não se encontrou nenhuma função resposta para expressar o comportamento desta característica (Tabela 1).

Para SST foi observado um comportamento decrescente desta variável em função do aumento das densidades populacionais da cenoura (Tabela 1). Esta variação foi de 7,9 para $7,4{ }^{\circ}$ Brix, portanto, diferente das encontradas por Machado et al. (2003), com as cultivares Nantes e Alvorada. Este comportamento pode ser explicado pela redução da taxa fotossintética por planta, causada pela maior competição entre as plantas de cenoura, decorrente do aumento da densidade de plantas, aliada à maior pressão de competição de dois cultivos sucessivos de alface associada à cenoura. Sabe-se que, altas densidades em hortaliças diminuem sua qualidade, pelo decréscimo no teor de SST, ocasionado pela redução na área foliar, conseqüentemente menor teor de açucares, principalmente a sacarose, afetando assim a qualidade das raízes de cenoura (NICHOLS, 1988). Não foi encontrada nenhuma função resposta para expressar o comportamento desta característica em função das densidades populacionais de alface (Tabela 1).

Para os açúcares totais e $\mathrm{pH}$ da cenoura, foram observadas curvas ascendentes em função do aumento das populações de cenoura (Tabela 1), atingindo os valores máximos de 3,25 e 6,18\% na população de cenoura de $100 \%$ PRCS, respectivamente. A concentração de açucares totais variou de 3,19 a $3,25 \%$ e o pH de 6,17 a 6,18. Esta variação da concentração de açucares foi diferente da obtida por Machado et al. (2003), com as cultivares Nantes e Alvorada. Não foi 
encontrada nenhuma função resposta para expressar o comportamento destas variáveis em função das densidades populacionais de alface (Tabela 1).

Para relação entre SST/ATT não foi encontrada equação de regressão que se ajustasse aos dados (Tabela 1).

Para produtividade comercial da cenoura foi observada uma superfície de resposta em função das densidades populacionais de cenoura e alface (Tabela 1). Um comportamento quadrático foi registrado na produtividade comercial em função das populações de ambas as culturas, atingindo o valor de 25,99 t/ha na combinação de $100 \%$ da PRCS da cenoura e $40 \%$ da PRCS de alface (Tabela 1). Este maior rendimento da cenoura, à medida que se aumentou sua densidade populacional, está diretamente relacionado ao maior número de plantas por área. Estes resultados concordam com os obtidos por Siqueira (1995), estudando o espaçamento de plantio na produção comercial de cenoura 'Brasília', no município de Mossoró, onde afirmou que a causa do aumento na produtividade comercial da cenoura em função do aumento da densidade populacional da mesma foi resultante do maior número de plantas por área de solo.

Com relação às produtividades da alface tanto no primeiro como no segundo cultivo, cresceram com o aumento na sua população, atingindo os valores de 22,77 t/ha e 7 t/ha na população de alface de $100 \%$ da PRCS (Tabela 1). Isto significa dizer que neste sistema de plantio a máxima produtividade de alface seria alcançada numa população superior à recomendada para cultivo solteiro (250.000 plantas/ha). Estes valores obtidos foram influenciados diretamente pelo maior número de plantas por área explorada pela cultura. Nenhuma função resposta foi encontrada para estas produtividades em função do aumento da população de cenoura (Tabela 1).

As maiores produtividades de cenoura e alface foram observadas na maior densidade populacional avaliada para cada cultura, chegando a uma produção de 25,99 t/ha de cenoura e 22,77 t/ha e 7 t/ha de alface nos dois cultivos sucessi-

Tabela 2. Correlação linear entre a produtividade comercial da cenoura e as características de qualidade avaliadas nas raízes da cenoura. Mossoró-RN, ESAM, 2003.

\begin{tabular}{clccc}
\hline $\begin{array}{c}\text { Produtividade } \\
\text { comercial }\end{array}$ & Características de qualidade & $\mathbf{r}$ & $\mathbf{t}$ & Probabilidade \\
\hline PC da Cenoura & Sólidos solúveis totais (SST) & $-0,535^{*}$ & $-2,369$ & 0,016 \\
PC da Cenoura & Acidez total titulável (ATT) & $-0,131$ & $-0,494$ & 0,314 \\
PC da Cenoura & Relação SST/ATT & $-0,164$ & $-0,623$ & 0,272 \\
PC da Cenoura & pH & 0,120 & 0,454 & 0,328 \\
PC da Cenoura & Açúcares totais & $0,491^{*}$ & 2,111 & 0,027 \\
\hline
\end{tabular}

* Coeficiente de correlação significativo ao nível de $5 \%$ de probabilidade pelo teste.

vos. Esses rendimentos estão na faixa dos encontrados por produtores e pesquisadores como Oliveira (2003); Bezerra Neto et al. (2003); Andrade et al. (2001) e Saldanha (2001) em trabalhos realizados nas condições de Mossoró.

Os resultados da análise de correlação linear entre a produtividade comercial da cenoura e os atributos ou características de qualidade das raízes encontram-se na Tabela 2. Pode-se observar que, entre as características avaliadas, as que se correlacionaram de maneira significativa com a produtividade comercial de cenoura, foram às concentrações de sólidos solúveis totais e açucares totais, evidenciando assim, que estes atributos podem ser considerados representativos da qualidade de raízes da cenoura como um todo, se considerados isoladamente.

\section{LITERATURA CITADA}

ANDRADE, F.V.; SANTOS JÚNIOR, J.J.; BEZERRA NETO, F.; NEGREIROS, M.Z. Desempenho de quatro cultivares de alface lisa em cultivo solteiro e consorciado com cenoura em dois sistemas de cultivos em faixas. Horticultura Brasileira, Brasília, v.19, n.2, Suplemento. CD-ROM. Trabalho apresentado no $41^{\circ}$ Congresso Brasileiro de Olericultura, 2001.

BAARDSETH, P.; ROSENFELD, H.J.; SUNDT, W.T.; SKREDE, G.; LEA, P.; SLINDE, E. Evaluation of carrot varieties for production of deep-fried carrot chips. I. Chemical aspects. Food Research International, v.28, n.3. p.195-200, 1995. BEZERRA NETO, F.; ANDRADE, F.V.; NEGREIROS, M.Z.; SANTOS JÚNIOR, J.S. Desempenho agroeconômico do consórcio cenoura $\mathrm{x}$ alface lisa em dois sistemas de cultivo. Horticultura Brasileira, Brasília, v.21, n.4, p.635-641, 2003.

CAETANO, L.C.S.; FERREIRA, J.M.; ARAÚJO, M.L. Produtividade de cenoura e alface em sistema de consorciação. Horticultura Brasileira, Brasília, v.17, n.2, p.143-146, 1999.
EMPRESA PERNAMBUCANA DE PESQUISA AGROPECUÁRIA - IPA. Recomendações de adubação para o estado de Pernambuco ( $2^{\mathrm{a}}$ aproximação). $2^{a}$ ed. Rev. Recife: IPA, 1998. 198 p. JANDEL SCIENTIFIC. Table Curve: curve fitting software. Corte Madera, CA: Jandel Scientific, 1991. $280 \mathrm{p}$.

MACHADO, C.M.M.; CARVALHO, P.G.B.; VIEIRA, J.V.; SILVA, J.B.C. Influência do espaçamento na quantidade de açucares e sólidos solúveis totais em cenoura. Horticultura Brasileira, Brasília, 2003. Disponível em: <http:// horticiencia.com.br/anais >. Acesso em: 25 jan. 2003. 10:55.

NICHOLS, M.A. Plant spacing to greater process vegetable crop productivity. Acta Horticulturae, v.220, n.74, p.223-228, 1988.

NORUSIS, M.J. SPSS/PC Statistics. Illinois: SPSS Inc., $1990.320 \mathrm{p}$.

OLIVEIRA, A.M. Bicultivo de alfaces americanas consorciadas com cenoura em dois sistemas de cultivo em faixas. 2003. 34 f. (Tese mestrado) ESAM, Mossoró-RN.

OLIVEIRA, E.Q. Desempenho agroeconômico do bicultivo de alface consorciada, em faixa, com cenoura. 2004. 76 f. (Tese mestrado) - ESAM, Mossoró-RN.

ROBINSON, R.W.; DECKER-WALTERS, D.S. Cucurbits. New York: CAB International, 1997. $226 \mathrm{p}$.

SALDANHA, T.R.F.C. Cultivares de alface crespa em sistemas solteiro e consorciado com cenoura. 2001. 41 f. (Monografia graduação) - ESAM, Mossoró-RN.

SEMENTES SAKAMA. Características de cultivares de alface. São Paulo: Sementes Sakama, 2002. 2 p. (Mimeografado).

SILVA, V.F. Cultivares de alface em diferentes espaçamentos sob temperatura e luminosidade elevadas na região de Mossoró-RN. 1999. 25 f. (Tese mestrado) - ESAM, Mossoró-RN.

SIQUEIRA, G.A.S. Espaçamentos de plantio na produção de cenoura "Brasília", no município de Mossoró-RN. 1995. 23 f. (Monografia graduação) - ESAM, Mossoró-RN.

VIEIRA, J.V.; VECCHIA, P.T.D.; IKUTA, H. Cenoura Brasília. Horticultura Brasileira, Brasília. v.1, n.2, p.42, 1983. 